\title{
Exploring Faculty Insights Into Why Undergraduate College Students Leave STEM Fields of Study- A Three-Part Organizational Self-Study
}

Araceli Martinez Ortiz, Ph.D., Texas State University, USA

Vederaman Sriraman, D. Eng., Texas State University, USA

\begin{abstract}
An institutional self-study at a Hispanic Serving Institution (HSI) explored factors thought to impact students' decisions to persist in science, technology, engineering and mathematics (STEM) fields of study. This self-study is presented as a model first step for Institutions of Higher Education interested in launching efforts to improve STEM education and STEM student success and persistence. A methodology combining qualitative and quantitative analysis approaches was used to examine different aspects of the overarching research question, "Why do undergraduate students leave college STEM fields of study?" A quantitative review of institutional data was used to identify four particular gaps in student persistence and success in STEM fields of study at Texas State University. An online survey and a focus group guide were developed based on existing but more broadly focused instruments and used to collect faculty insights regarding faculty and student experiences and possible reasons for student attrition in STEM. A review of retention theories was undertaken to better inform the process of generating remedies to the STEM persistence issue. Data were collected and analyzed separately for each component to produce two sets of findings. Findings indicated that there were retention issues in regard to STEM majors in general and underrepresented student groups in particular. Underrepresented students do not pursue STEM degrees percentage wise in comparison to other degrees. The self-study and retention theories suggest the following remedial measures: supporting faculty to transform their teaching, providing supplemental instruction in math and science and including discipline specific introductory courses and early internship experiences.
\end{abstract}

Keywords: Persistence Of College Students; STEM; Organizational Self-Study; Faculty Surveys; Engineering Education

\section{INTRODUCTION}

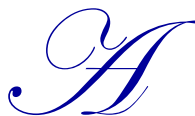
ccording to a recent report by the President's Council of Advisors on Science and Technology (PCAST, 2010), over the next decade the nation will have a serious shortage of STEM college graduates. This report estimates the shortage to be a million STEM college graduates. Maltese and Tai (2011) report that while the overall award of undergraduate degrees in the nation has increased by a factor of three, this is not the case in the case of STEM disciplines. In fact, according to the National Science Foundation, in 2006 the relative percentage of students receiving STEM degrees were at levels no different or lower than those of the past ten years (NSF, 2012).

However, according to the Bureau of Labor Statistics (2014) by 2018, more than 3 million job openings will be created in STEM disciplines. The Department of Commerce (2012) estimates that in the coming years STEM occupations will grow 1.7 times faster than non-STEM occupations. Thus, there is a critical need to remedy this shortage of STEM professionals so as to ensure continued growth in the economy. Although various sources (Teitelbaum, 2014) and (Charette, 20130) challenge the shortage argument, They do admit to the great importance 
of science and engineering occupations towards a globally focused U.S. economy and the crucial nature of developing a supporting professional workforce. This self-study will focus on the comparison of STEM students to non-STEM students and using this local lens, it does indeed support the notion that the STEM career preparation pipeline is leaky and there is a need to understand the reasons why a significant number of STEM students do not complete their course plans of study.

Texas State University (Texas State) is located in San Marcos, Texas. San Marcos is located in central Texas about mid-way between San Antonio and Austin, Texas. San Antonio is a historic center of Hispanic culture and Austin is a base for high-technology industries in Texas. Elsewhere in the state, such as in the greater Houston and Dallas/Fort Worth areas, are large centers of petrochemical and high technology industries respectively. The State of Texas has enjoyed one of the most robust economies in the nation over the last decade, even as most of the nation was under the spell of a downturn in economy. However, this growth is not sustainable without an adequate supply of STEM professionals.

Texas is the second most populous state in the nation, surpassed only by California and followed by New York. According to the Texas Comptroller of Public Accounts (2012), Texas is one of the fastest growing states in the nation. Since 2000 , the state's population has increased by $12.7 \%$, nearly twice that of the nation. The U.S. Census Bureau data indicate that Hispanics/Latinos accounted for 38.2\% of Texas's population in 2012. This makes this group the second largest in the state. According to the Pew Research Center (2014), Hispanics will likely become the largest group in the state within ten years, outnumbering whites. Similar projections have been made at the national level as well. According to the U.S. Census Bureau, by the year 2050 African American, Hispanic, Asian and Native American populations will account for $50 \%$ of the total U.S. population (U.S. Census Bureau, 2013). Thus, while it is imperative that the number of STEM graduates in Texas be increased it is equally important to accomplish this outcome in the context of the increasing Hispanic population in the state. One approach to pursue is to focus on retaining undergraduate students of diverse backgrounds who are currently in STEM fields of study and to support them to successfully graduate. In the following section, retention theories that address this goal are presented.

\section{BACKGROUND}

Included in this section is a review of research on "retention" and on "persistence". Formally, theories of retention deal with institutional efforts, while those of persistence deal with individual student behavior (Reason, 2009). In this paper, we draw upon findings from both bodies of literature to shed light on the totality of the factors that influence "why students leave college STEM fields of study".

\section{Theories on Student Persistence and Factors of Influence}

When college student retention theories first evolved some 45 years ago, the issue was viewed through the lens of psychology. Student retention was thought to be a function of individual motivation, attributes, and skills. Thus, there was the notion that students failed, not institutions (Tinto, 2007). From the 1970s onward, this view of retention yielded to one that focused on the relationship between students and society. As a result, greater emphasis was placed on the role of institutions in students' decisions on whether to stay or leave (Spady, 1971). Since then, several major theories/models have tried to explain student retention/attrition; the Center for the Study of College Student Retention lists as many as eight. Of these, two have dominated the theory and practice of retention:

1. Tinto's academic and social integration model (Tinto, 1975, 1987, 1993) and

2. Astin's involvement model (Astin, 1975, 1977)

Tinto's Model of Academic and Social Integration

Tinto's model has paved the way for a sociological analysis of retention that has been popular for several decades (Noel-Levitz, 2012) and postulates that persistence occurs when students successfully integrate into the institution academically and socially. Integration, in turn, is influenced by pre-college characteristics and goals, interactions with peers and faculty, and out-of-classroom factors (Jensen, 2011). Additionally, Tinto argues that the 
first year of college, indeed the first semester, is critical to students being incorporated into the college campus, as well as their eventual persistence through to graduation. Retention programs, therefore, are most successful when they utilize informal faculty-student contact in order to integrate students into the mainstream of the academic and social life of the college (Longwell-Grice, and Longwell-Grice, 2007).

\section{Astin's Involvement Model}

Astin's model, based on patterns of behavior exhibited by successful students, asserts that the keys to success and graduation are involvement and connection. Involvement refers to both formal academic or intellectual pursuits as well as co-curricular activities. Among the primary measures of academic involvement is time spent on academic studies and tasks, and the development of higher cognitive skills. Co-curricular involvement includes measures of participation in campus activities and membership in academic/honors associations and social clubs. Connection refers to bonding with peers, faculty, and staff as well as sharing the institution's values (Noel-Levitz, 2012). Tinto's model was based on traditional students in traditional residential institutions. Many scholars have modified Tinto's original model to address the role of the institution in the social and cultural integration and retention of minority students. Challenging the perspective in Tinto's model that retention depends on the student's ability to integrate and assimilate into the institution, other researchers have offered the concept of dual socialization (Rendón et al., 2004) and (Kuh and Love, 2004). Students who make cultural connections through social groups that reflect their culture of origin are more likely to persist in higher education. Tierney's model of persistence suggests that institutions need to provide to their students the cultural capital necessary to succeed in an educational system where barriers to persistence and integration exist for minority students (Tierney, 2004 ).

\section{Pascarella and Terenzini's Framework for Persistence Research}

Some researchers have provided a "comprehensive conceptual framework" for persistence research. Pascarella and Terenzini (2005) based on thirty years of research have concluded that multiple factors in multiple settings affect student learning and persistence. Accordingly, changes of any particular variable or set of variables during undergraduate years may not be as significant as the effect of interconnected changes. These researchers have also suggested that most studies of the college effects on students have adopted an "overly narrow" focus, in that only a handful of factors have been considered. This in turn leads to a body of evidence that "present only a partial picture of the forces at work".

Terenzini and Reason have advanced such a comprehensive and integrated model for studying student learning and persistence. Their framework extends and synthesizes models by Astin, Tinto and Pascarella and is illustrated below. 


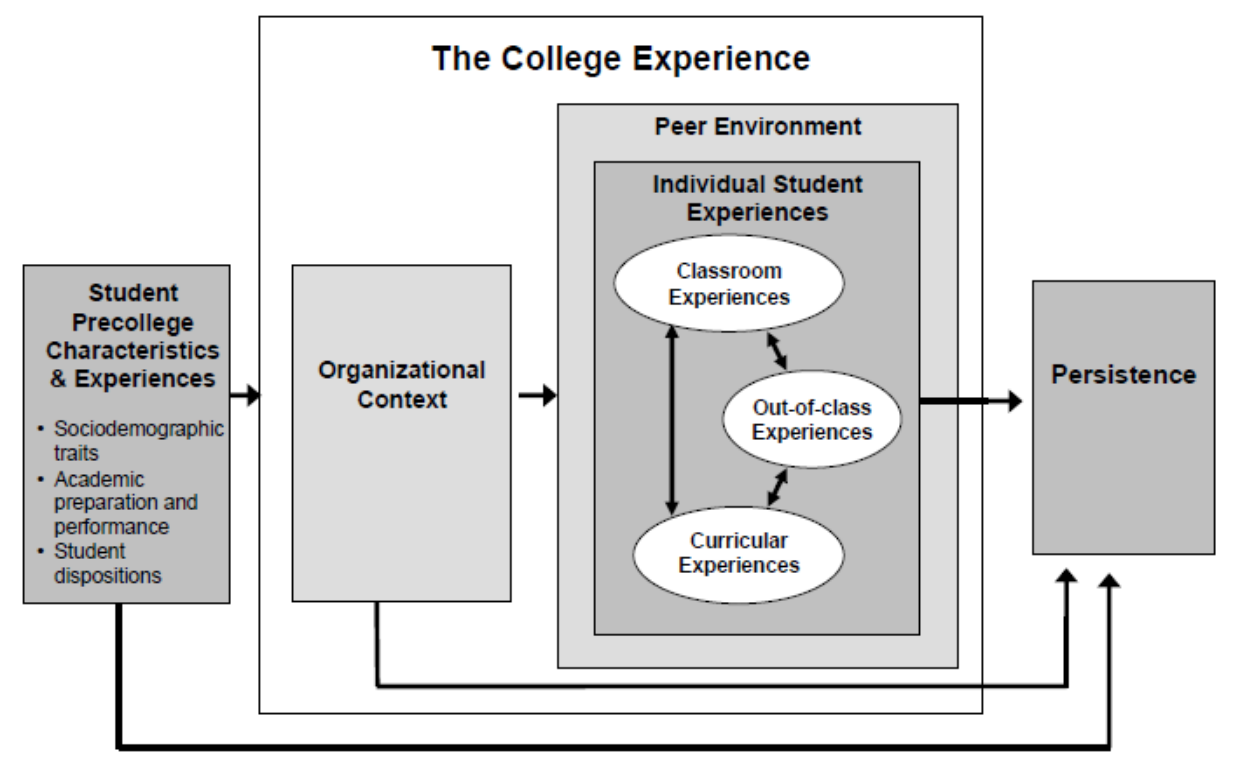

Figure 1. Comprehensive Model for Persistence Research [From Reason, R. D. (2009). An examination of persistence research through the lens of a comprehensive conceptual framework. Journal of College Student Development 50(6), 659-682.]

This framework arranges into four groups the wide range of factors that influence student learning and persistence. These include:

1. Student precollege characteristics and experiences

2. The organizational context

3. The student peer environment

4. The individual student experience

Higher education researchers are encouraged to look more broadly at the multiple forces that affect college student outcomes (Pascarella and Terenzini, 2005). STEM student retention concerns can be analyzed using this framework. Such STEM retention analysis is presented in the following section.

\section{STEM Student Retention Issues at the National Level}

Studies indicate that while underrepresented minorities in STEM now account for almost $40 \%$ of K-12 students in the U.S., they earn only $17 \%$ of the bachelor's degrees in science and engineering (S\&E) (Committee on Underrepresented Groups and the Expansion of the Science and Engineering Workforce Pipeline, 2010.). In particular, data also suggest that while the number of Hispanic students participating in postsecondary education has been on the rise, percentage wise, Hispanics are underrepresented from standpoints of pursuing and attaining STEM degrees (Young, 2005). Research also reveals that Hispanics are less likely to earn undergraduate degrees in biological and life sciences, computer and information sciences, and the health professions and related sciences (Nora and Crisp, 2009). Indeed, NSF data indicate that of 436,372 bachelor's degrees awarded in S\&E to U.S. citizens and permanent residents, only $7.3 \%$ were earned by Latino students. Significantly larger percentages (65.1\%) of White, non-Hispanic students earned S\&E degrees (NSF, 2006). Data from the Higher Education Research Institute indicates that $16 \%$ of Hispanics who began college in 2004 as STEM majors completed a STEM degree by 2009, in contrast to White students who did so at the rate of 25\% (Higher Education Research Institute, 2010). Within the Latino population there is disparity in participation between males and females. Latinas are underrepresented in STEM disciplines even though they enroll in college at greater number than Latinos (NCES, 2005). 


\section{SELF STUDY PART 1- STEM STUDENT RETENTION DATA ANALYSIS}

\section{STEM Student Retention Issues at Texas State University}

The first part of this self-study was an in-depth multi-year data analysis of student retention statistics for STEM students at Texas State University. Such an analysis is important to the institution and should also prove to be very relevant to the national dialogue on STEM retention. According to the Institute for Higher Education Policy (2012), Minority Serving Institutions (MSIs) are key intermediaries to improving the quality, availability and diversity of the STEM educational pipeline (IHEP, 2012). Also, HSIs are responsible for awarding nearly $40 \%$ of all bachelor's degrees conferred to Latinos. Thus, HSIs are positioned to provide important pathways to STEM fields by virtue of the large number of Latinos they serve (Dowd et al., 2009). By way of definition, HSIs are those institutions where Latinos account for $25 \%$ or more of the full-time equivalent enrollment. Research also indicates that $20 \%$ of the bachelor's degrees awarded to Latinos in STEM fields are from HSIs. Texas State University, a large public university whose overall enrollment has grown over $45 \%$ over the past ten years (from 25,025 in fall 2003 to 34,225 in fall 2013), has a long-standing tradition of serving Hispanic students and was designated as a HSI in 2012 (Dowd et al., 2010).

\section{STEM Classification of Instructional Programs}

The category of science, technology, engineering and mathematics fields of study, identified by the acronym STEM, can be defined in many different ways. The taxonomy developed by the U.S. Department of Education's National Center for Education Statistics (NCES, 2002) offers a useful coding for the Classification of Instructional Programs (CIP) and provides a scheme to support the accurate tracking, assessment, and reporting of fields of study and program completions activity. The NSF definition includes 9 CIP codes (NSF, 2014), however, in order to provide a clear but narrow focus, in this study, STEM is defined using the combination of CIP codes that is defined by the State of Texas Higher Education Board (THECB, 2013) to describe physical science and engineering majors; the following 4 digit codes and majors are included in this definition:

Table 1. STEM CIP Codes Included

\begin{tabular}{ll}
\hline 11.01 & Computer Science \\
\hline 14.10 & Electrical Engineering \\
\hline 14.35 & Industrial Engineering \\
\hline 14.36 & Manufacturing Engineering \\
\hline 15.00 & Engineering Technology \\
\hline 15.06 & Ind Tech Manufacturing Tech \\
\hline 15.10 & Industrial Technology \\
\hline 15.10 & Concrete Industry Management \\
\hline 15.10 & Construction Sci \& Mgt \\
\hline 27.01 & Ind Tech Construction Tech \\
\hline 30.01 & Mathematics \\
\hline 40.05 & Applied Mathematics \\
\hline 40.08 & Science \\
\hline
\end{tabular}

Using this definition for STEM, and limiting the analysis to include only undergraduate majors in STEM, the following chart shows that of the 2,177 STEM majors, $87 \%$ of STEM majors were in 8 majors (computer science, electrical engineering, mathematics, engineering technology, construction science and manufacturing, chemistry, industrial engineering and manufacturing engineering). 


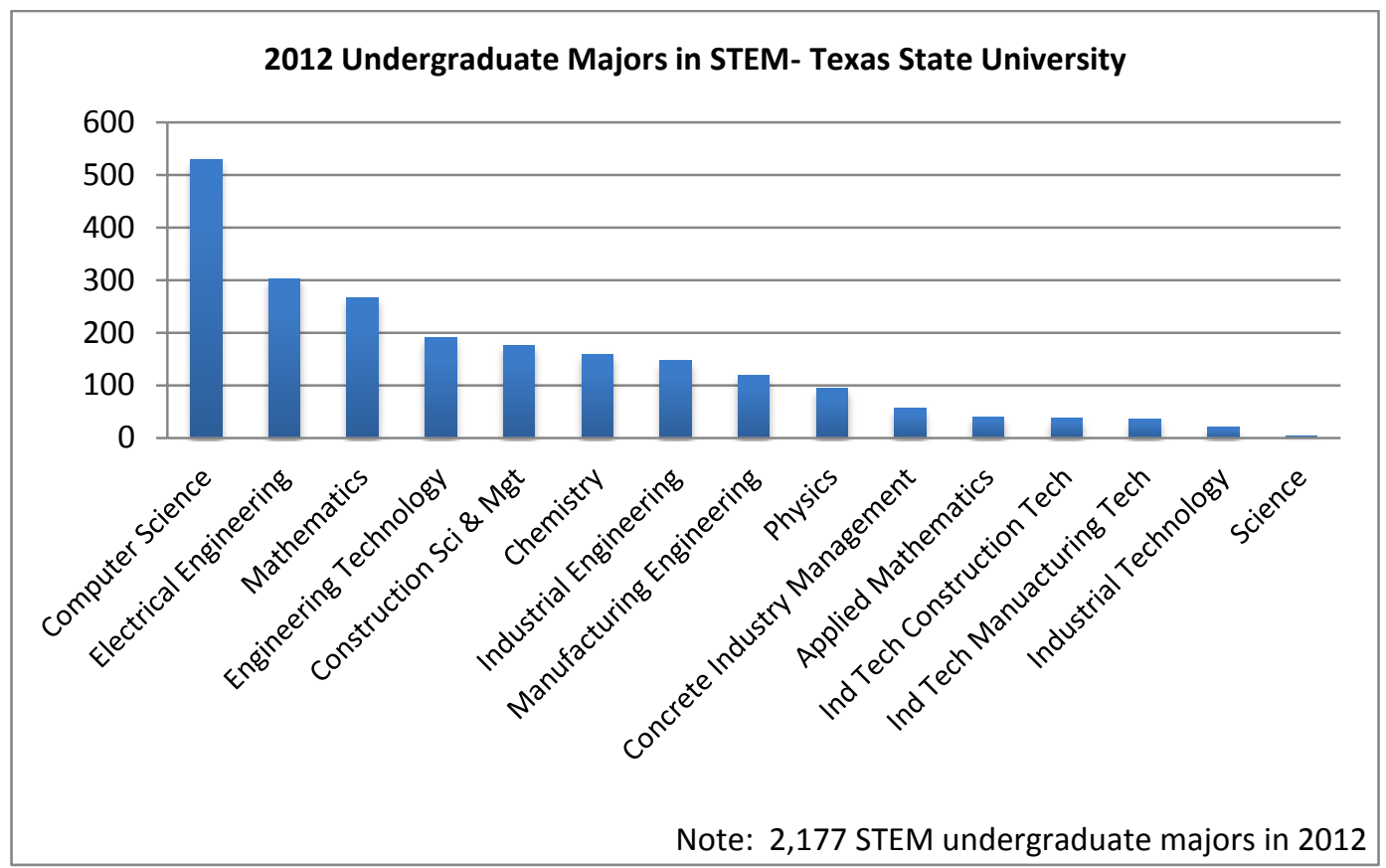

Figure 2. Distribution of STEM Majors at Texas State University

In 2012, STEM majors constituted about $7.4 \%$ of the overall undergraduate student population at Texas State $(2,177$ of 29,458$)$.

\section{Texas State University Student Body Demographics}

In Fall 2013, Hispanics made up 29\% of the undergraduate population, African American students made up $7 \%$, and White students represented $57 \%$ of the population.

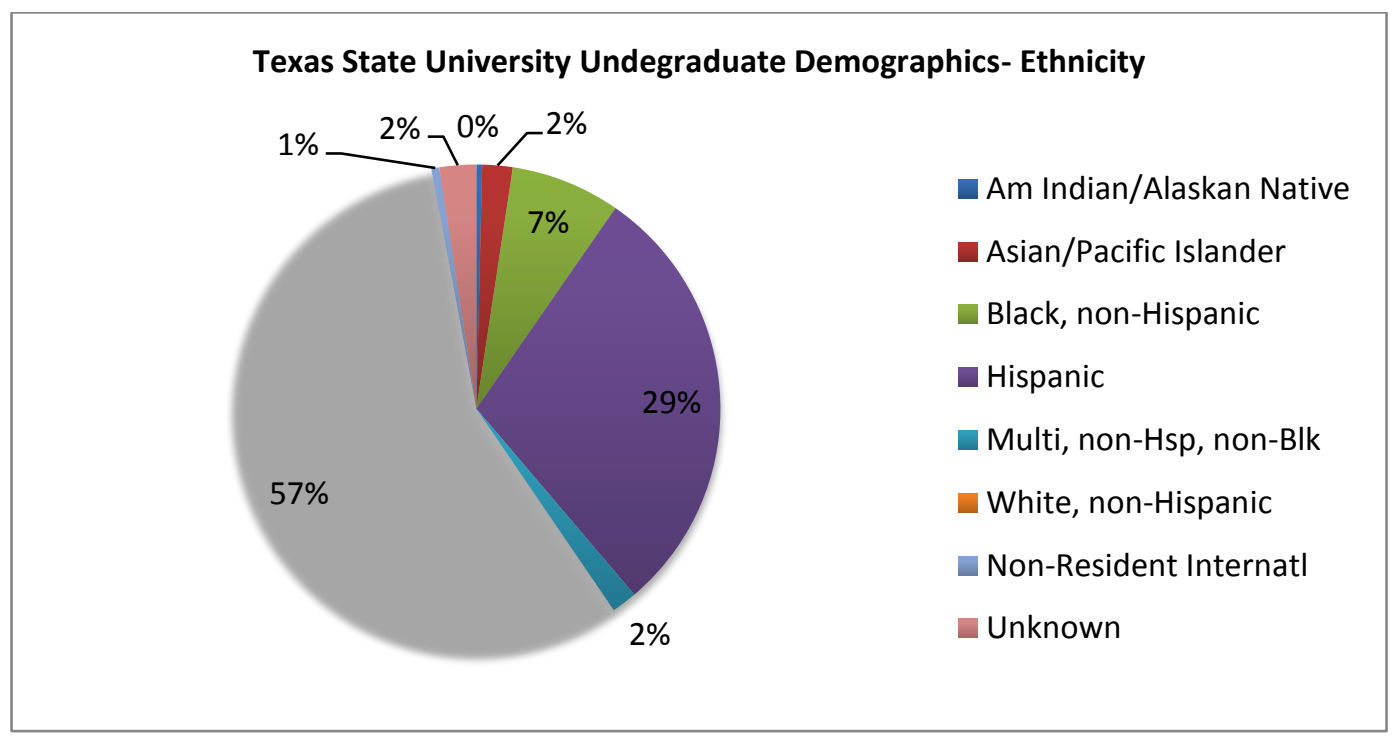

Figure 3. Demographics of STEM Majors at Texas State University 
However, the Hispanic or Latino enrollment has increased at a greater rate than the overall enrollment, resulting in a doubling of the number of Hispanic students. In 2003, Texas State had 4,822 Hispanic undergraduate students. By 2013, that number had grown to 9,558 , a $113 \%$ increase. The chart below depicts this growth.

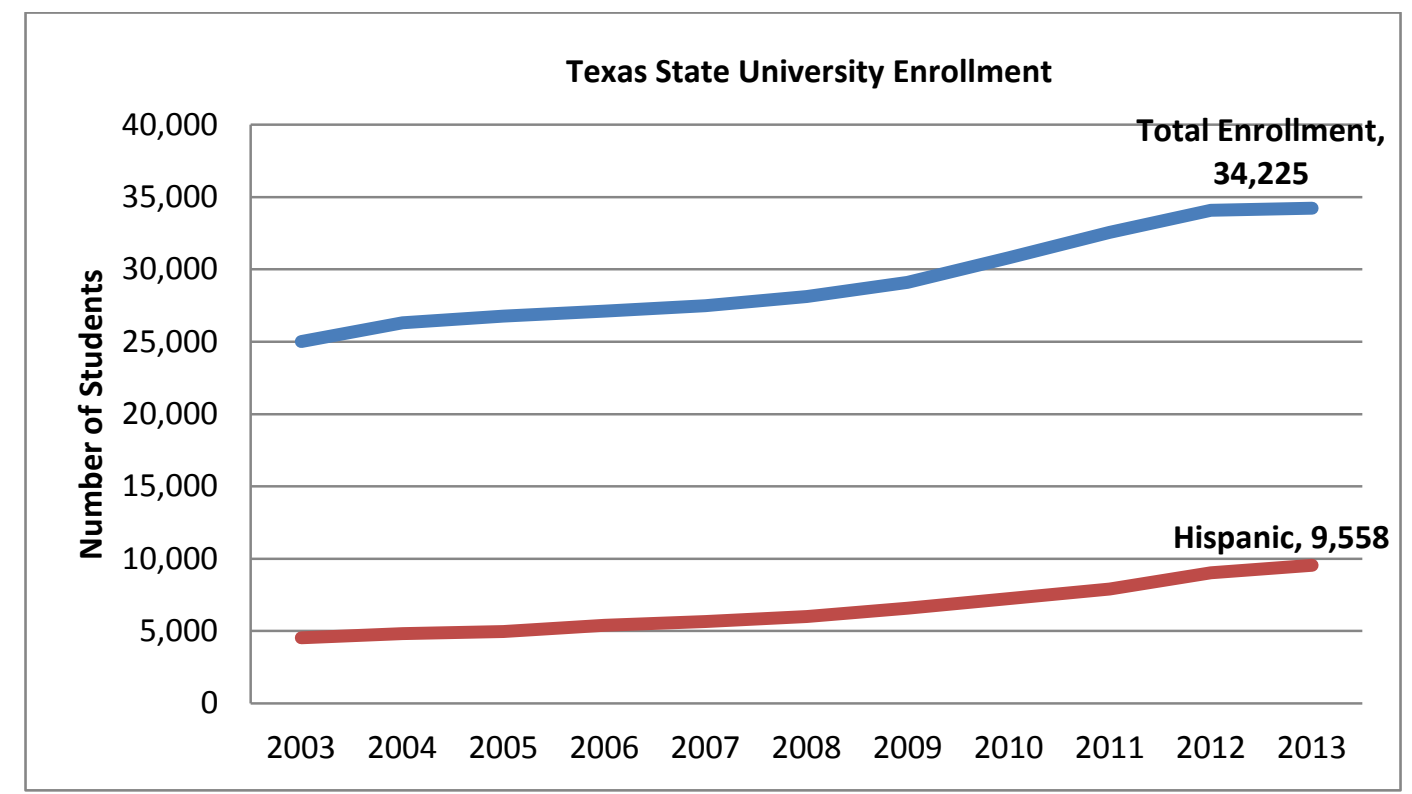

Figure 4. Texas State University Enrollment

Through analysis of retention rates by ethnicity and gender, several gaps were detected; Table 1 identifies those that will be addressed as part of this project.

Gap 1: STEM majors are not proportionately retained in their chosen field of study. While $67 \%$ of 2nd-year students are retained in their chosen field of study, only 56\% of 2nd-year STEM majors are retained in their chosen field of study.

Gap 2: Hispanic and African American STEM majors not proportionately retained in STEM. While 60\% of 2nd-year White STEM majors are retained in STEM, only 46\% of 2nd-year Hispanic and African American STEM majors are retained in STEM. 


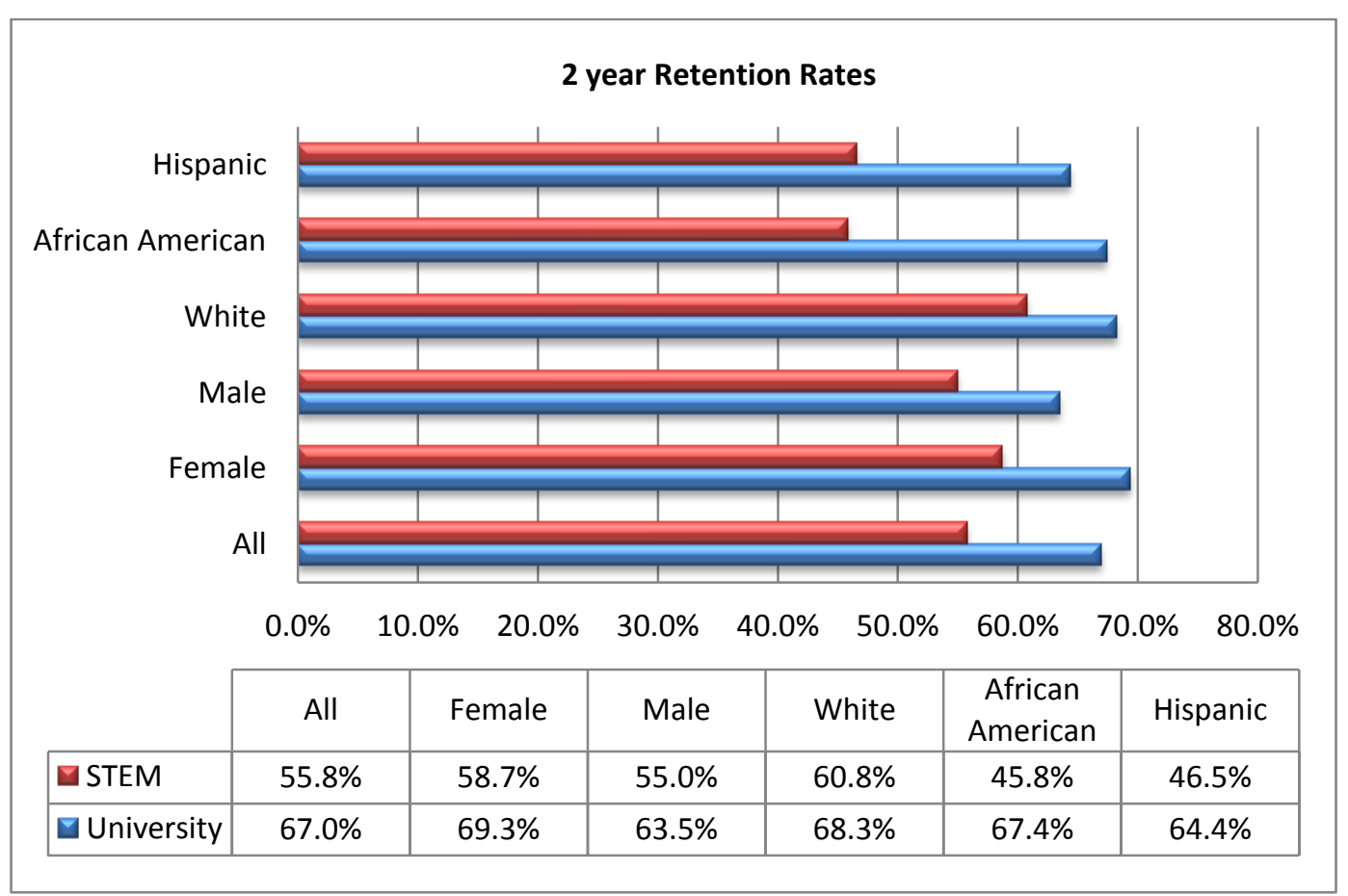

Figure 5. Overall Retention Rate Demographics at Texas State University

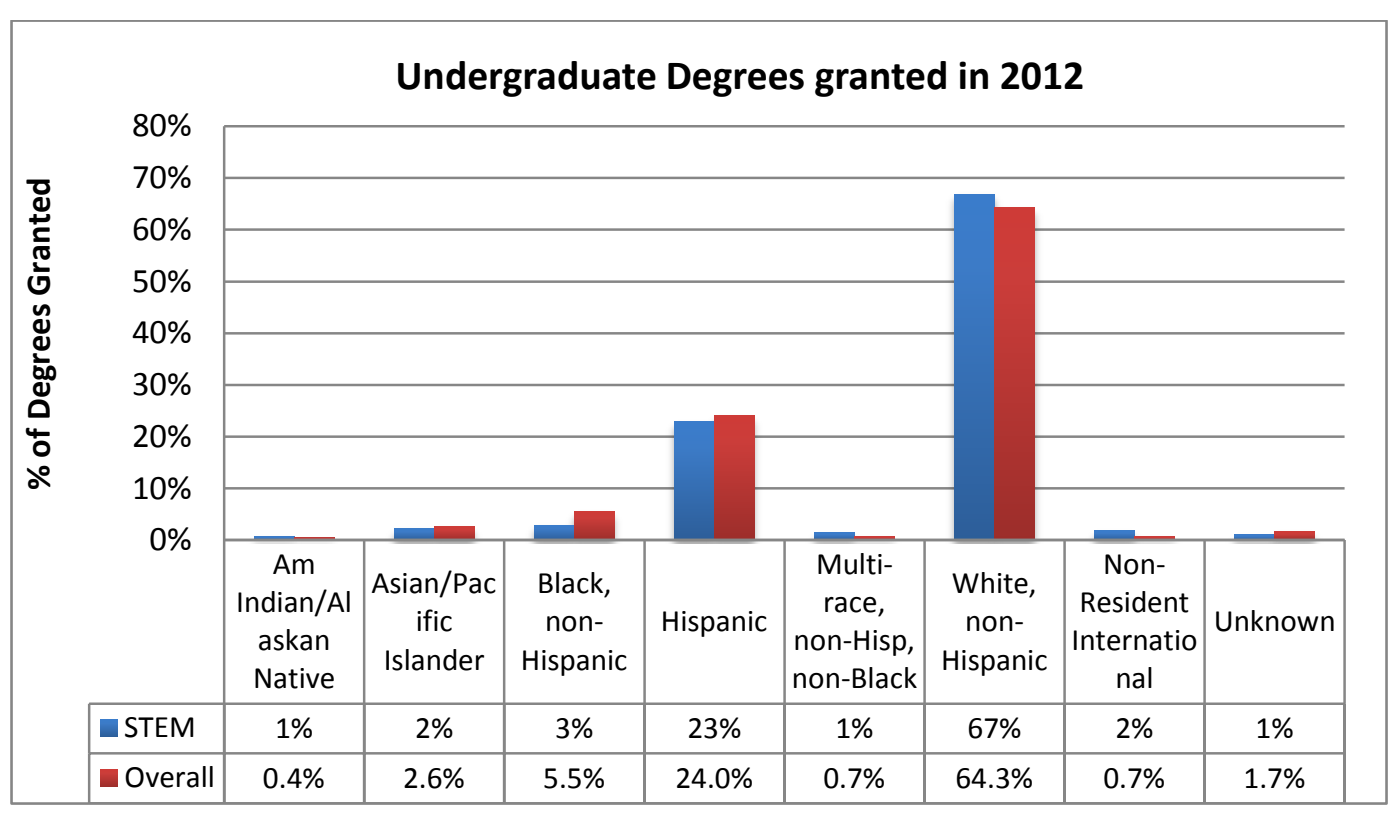

Figure 6. Degrees Granted by Ethnicity at Texas State University

Further to this issue, however, is the fact that the time to graduation is much slower for African American and Hispanic students. In the 2006 cohort, for example, we see that almost $20 \%$ of all White students in STEM graduated within four years, while only $7 \%$ of Hispanic students graduated within four years, and none of the African American students graduated within four years in that cohort. Even when allowing for a six year time to completion, $46 \%$ of all White students graduate within six years, while only $33 \%$ of Hispanic students graduated and only $17 \%$ of the African American students graduate within six years in that cohort. 


\begin{tabular}{|l|c|c|c|}
\hline \multicolumn{3}{|c|}{ STEM Student Cohort Graduation Rates [2012] } \\
\hline Years & White & Black/African American & Hispanic/Latino \\
\hline $4 \mathrm{yrs}$ & $19.8 \%$ & $0.0 \%$ & $6.7 \%$ \\
\hline $5 \mathrm{yrs}$ & $39.7 \%$ & $0.0 \%$ & $26.7 \%$ \\
\hline $6 \mathrm{yrs}$ & $45.5 \%$ & $16.7 \%$ & $33.3 \%$ \\
\hline
\end{tabular}

Figure 7. STEM Student Cohort Graduation Rates

Gap 4: Female students are not proportionately represented in STEM majors. While 55\% of undergraduate students are female at Texas State University, only 16\% of STEM majors are female.

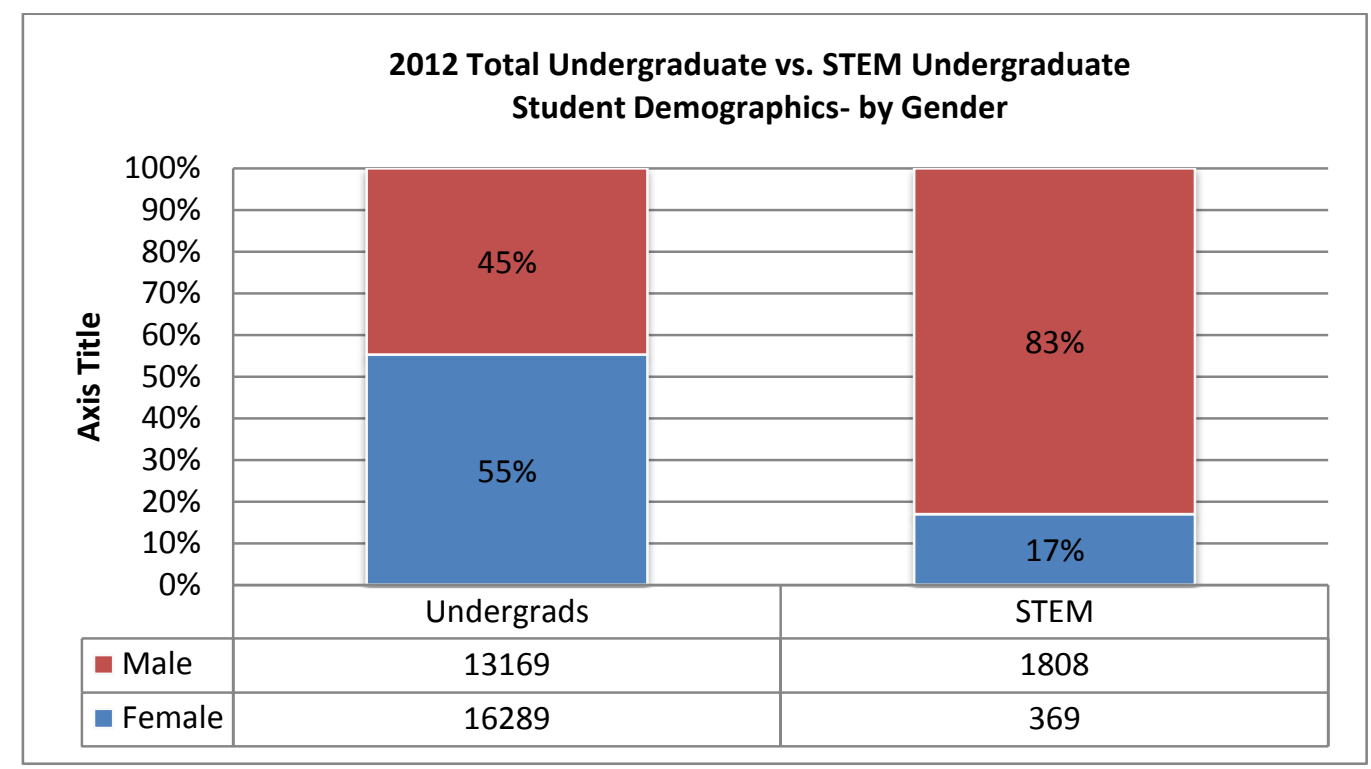

Figure 8. Student Demographics by Gender at Texas State University

\section{SELF STUDY PART 2- FACULTY ONLINE QUANTITATIVE SURVEY}

\section{A Survey of STEM Faculty}

The second part of this self-study was an online survey designed to collect information and opinions from a small group of faculty from the College of Science and Engineering at Texas State University. Their perceptions regarding why some undergraduate STEM students do not persist are important and contribute to a broader understanding of the STEM higher education system. An anonymous survey was developed based on a considerable body of research that suggests that faculty have a unique perspective and indeed can have a significant impact in the support and retention of a diverse student body (Davis \& Finelli, 2007; Nadelson \& Callahan, 2012). The survey was developed to help describe a set of factors that faculty and administrators identified as contributing to why STEM students leave their field of study. Further, major themes describing their recommendations for improvement were also discussed.

\section{The Participants}

Participants were nominated by their department chairs and then self-selected to participate in the online survey. Within the survey introduction they were provided with full research disclosure information. Twelve faculty members participated in all. While the sample size is relatively small, the sample is very representative in all aspects of faculty demographics to include the variety of academic units in the college, academic rank, and tenure at Texas State. All of the faculty members are also involved in academic advising. Thus, the authors are confident that the sample size notwithstanding, reliable input was obtained. The demographics of the faculty who responded were self-reported as summarized in the following figures 8-10: 


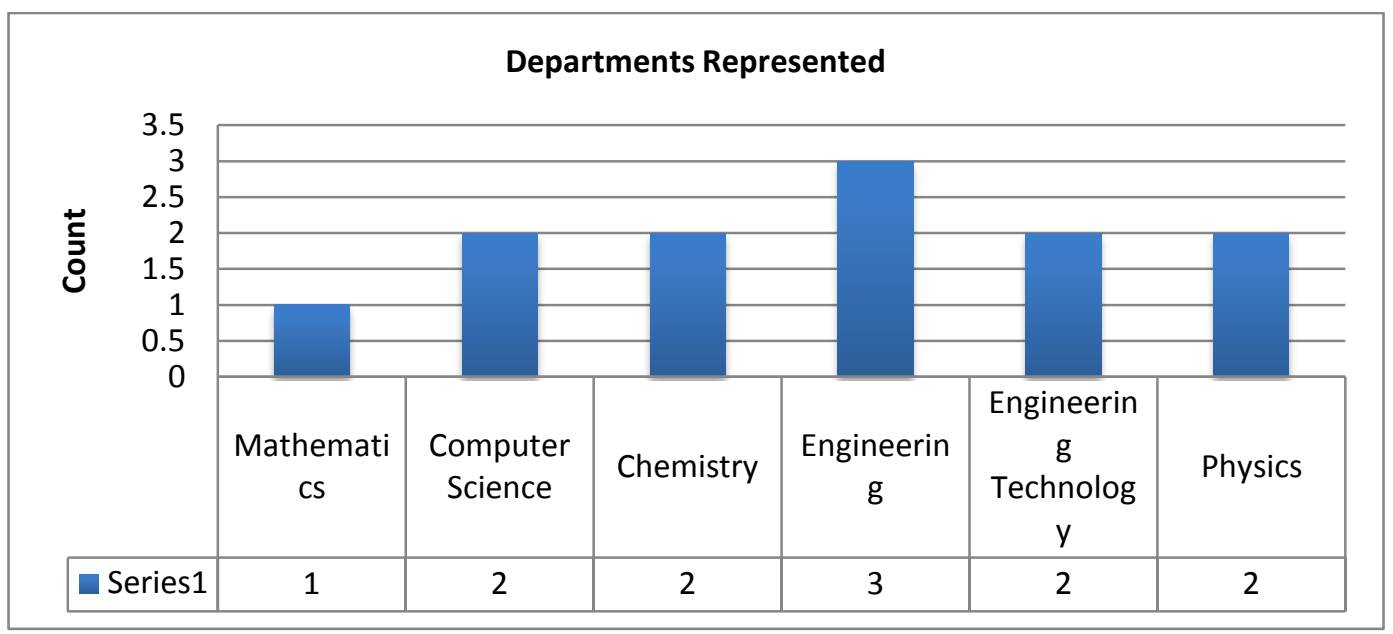

Figure 9. Department Represented by the Participating Faculty

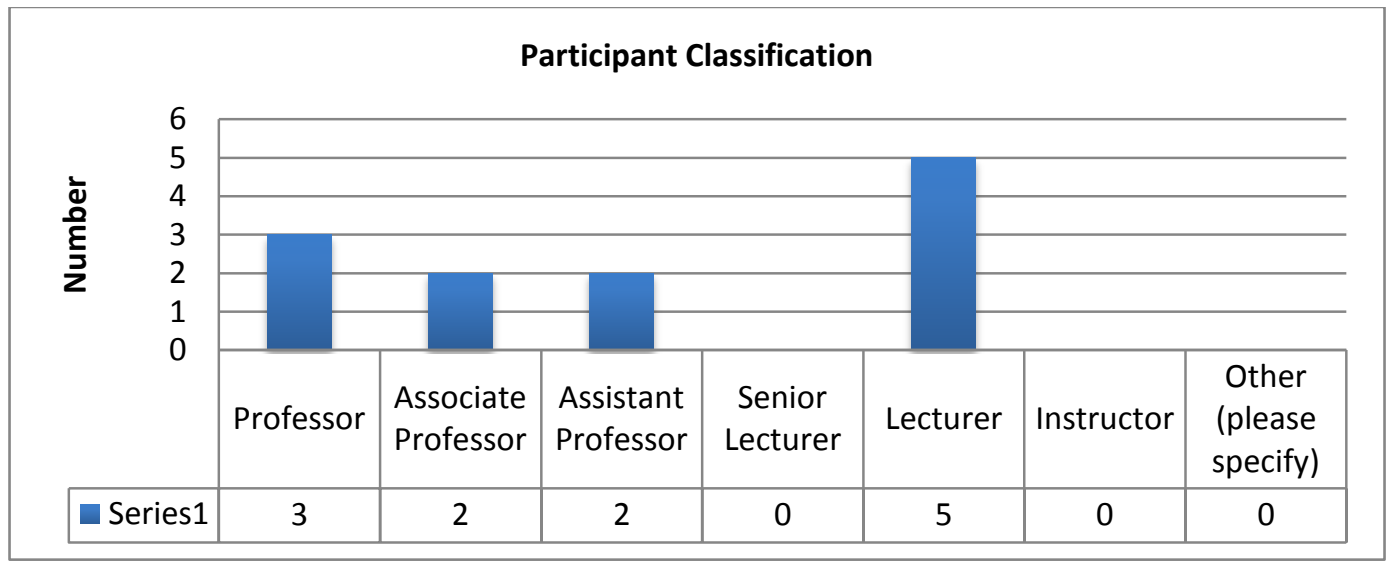

Figure 10. Employment Classification of the Participating Faculty

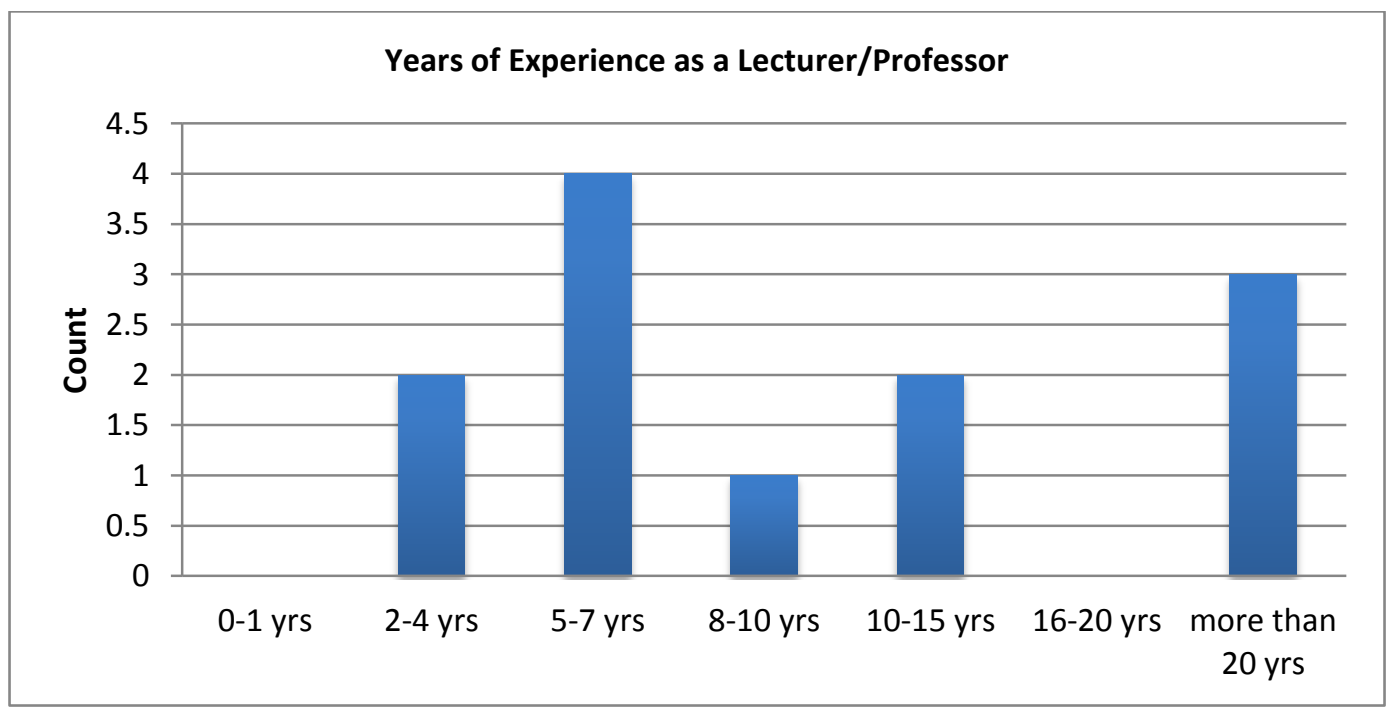

Figure 11. Years of Experience as a University Lecturer/Professor of the Participating Faculty 
The Study Procedure

This first online survey administration was meant to serve as a primary source of data from a targeted group of faculty and as a pilot of the instrument for the first phase of this STEM self-study initiative. A presentation of the initiative was made to a department leadership team. These department heads subsequently invited 2-3 members of their department to participate in the online survey. The selected individuals are described above but ranged in gender, department, position, and years of experience. These individuals were contacted and provided an overview of the survey by the researcher and sent a link to the online survey. The online survey itself was used to capture consent, background information, perceptions and insight, and specific recommendations.

\section{The Instrument- Faculty Perceptions on Student Retention (FPSR) Online Survey}

A 25-question survey, the Faculty Perceptions on Student Retention (FPSR) survey was developed based on modified questions from two research based instruments, one focused on general undergraduate faculty opinionsHurtado et al's (2012) undergraduate faculty survey, and the other based on STEM faculty attitudes and opinionsLundquist, Spalding and Landrum (2002). An outline of the categories of questions contained in the survey is shown in the table below.

Table 2. Categories of Questions in the Faculty Perceptions on Student Retention survey

\begin{tabular}{|c|c|}
\hline Questions & 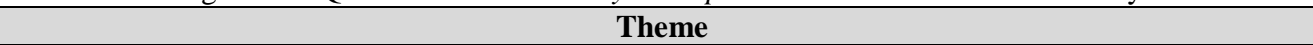 \\
\hline $1-7$ & Faculty Demographics \\
\hline $8-10$ & Individual Teaching Circumstances \\
\hline $11-20$ & $\begin{array}{l}\text { Indicate how well each of the following describes Texas State University College of Science and } \\
\text { Engineering: } \\
\text { - Accessibility of faculty to students } \\
\text { - Professional faculty relationships } \\
\text { - Perceptions of faculty by students } \\
\text { - Respect for faculty expression of diverse values and beliefs } \\
\text { - Faculty rewarded for good teaching } \\
\text { - Faculty rewarded for use of instructional technology } \\
\text { - Administrators consideration of faculty concerns in policy development } \\
\text { - Administration's level of openness regarding policy } \\
\text { - Faculty interest in students' personal problems }\end{array}$ \\
\hline $21-72$ & $\begin{array}{l}\text { Faculty Perceptions Regarding: } \\
\text { - Instructors in General and Curriculum } \\
\text { - Students- Academics and Leadership } \\
\text { - } \quad \text { Student- Advising and Study Skills } \\
\text { - The Institution; Research; Instruction; Community } \\
\text { - } \quad \text { Diversity in Faculty; Diversity in Students/Environment } \\
\text { - Respect and Involvement of Faculty } \\
\text { - Faculty Support, Development and Career }\end{array}$ \\
\hline $73-82$ & $\begin{array}{l}\text { Indicate how important you believe each student-related factor to be in influencing a student's } \\
\text { decision to persist in a Science, Technology, Engineering, and Mathematics field of study at Texas } \\
\text { State University: } \\
\text { - Student high school academic achievement (GPA, class rank) } \\
\text { - Student academic aptitude as evaluated by college entrance score achievement (SAT/ ACT/ } \\
\text { - Placement test scores) } \\
\text { - Study Habits (self study practices, group study, attendance, use of resources) } \\
\text { - Commitment to Career and Educational Goals } \\
\text { - Comfidence in Quantitative Skills ( computer skills, mathematical ability, etc) } \\
\text { - Financial Needs } \\
\text { - Family Support } \\
\text { - Social Engagement }\end{array}$ \\
\hline
\end{tabular}


Data was collected from a sample size group of 12 faculty of Texas State University's college of science and engineering. These surveys were administered using an online survey tool and were returned anonymously by the participants. This research involved the use of personal information and opinions of faculty members in the College of Science and Engineering. The information obtained was recorded in such a manner that human subjects were not identified, directly or through identifiers linked to the subjects. Thus, any disclosure of the human subjects' responses outside the research was not identifiable and is reported in general aggregate. In addition to the data findings presented below, a series of focus groups were organized to gather qualitative discourse data from the invited faculty. The qualitative survey is discussed in the next section entitled "Self Study Part 3".

\section{Analysis of the Quantitative Research Data.}

Survey data was collected and is highlighted below. Figure 11 shows the factors that most faculty rated as very important in influencing a student to persist in STEM studies. Of the twelve faculty polled, the top factors selected were Study Habits (11), Confidence in Quantitative Skills (computer skills, math ability, creativity) (10), Commitment to Career and Ed Goals (10), Student Academic Achievement (GPA, etc.) (8) and Family Support (8).

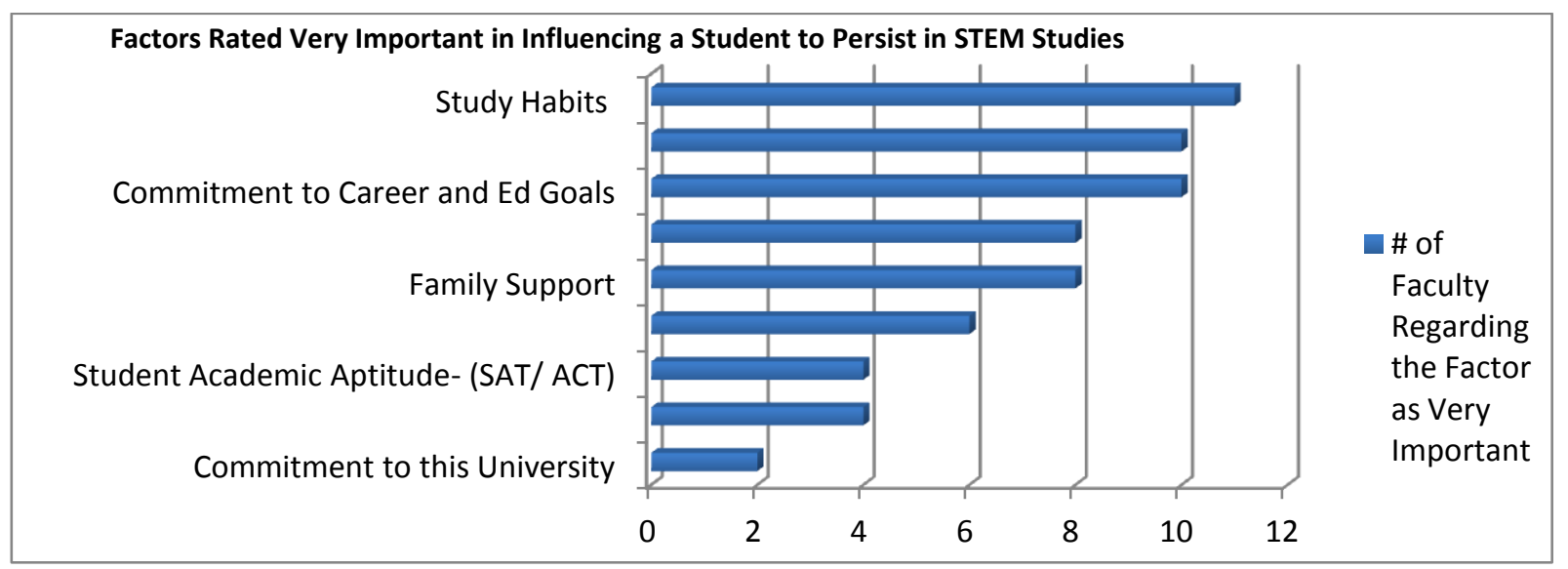

Figure 12. Factors rated very important in influencing a student to persist in STEM studies Additional data is discussed in a separate publication (Martinez Ortiz and Sriraman, 2014).

\section{SELF-STUDY PART 3- A FOCUS GROUP WITH FACULTY}

\section{A Focused Discussion with STEM Faculty}

In addition to the quantitative self-study, a qualitative study was organized and conducted. This supporting analysis of faculty perceptions regarding why undergraduate STEM students do not persist at high rates was undertaken as a qualitative approach to help answer the research question R1: What factors do faculty and administrators at Texas State University attribute as to why STEM students leave their field of study, and what recommendations do they suggest for improvement.

\section{The Participants}

The study comprised two focus group sessions that were held with an 18-member faculty focus group - two from every STEM discipline - to understand why students leave STEM disciplines. This group of faculty was very experienced working with STEM students in their first- and second-year courses. There was a general consensus that student retention was an issue of great concern at Texas State University and that underlying causes included: an unwelcoming environment, large class sizes, high school academic under-preparedness in mathematics and science by many students, and insufficient support in instructional methodology by a substantial amount of faculty. This effort revealed and confirmed a number of trends related to students as they progress throughout their STEM studies. 
The Study Procedure

The procedure involved each faculty member to participate in a 90 minute guided and facilitated group conversation. Faculty members were asked to share their personal opinions and perceptions regarding the culture of the College of Science and Engineering in general. In addition, they were asked for their insights as to challenges and opportunities regarding STEM student persistence.

Faculty members were advised that their responses would only be noted for analysis but would not be attributed to individuals. Only written notes without speaker attributions were recorded, transcribed, and stored in a password protected electronic format. The research has been designated as exempt from full IRB review involving human subjects.

\section{The Instrument- the Qualitative Study Focus Group Guide}

Two focus group sessions were organized for a one-hour time period. The focus group facilitator utilized the outline shown in Table 2 to serve as a guide for the focus group discussion:

Table 3. Faculty Focus Group Guiding Questions

1) Is there a problem?

National and State data suggests that student retention in the STEM fields is a problem on many college campuses, and that within the first two years of study, students who have expressed an intent to major in a STEM field, switch out at rates of up to $50 \%$ - they do not persist. Do you believe this to be a problem at Texas State University and if so, to what extent?

2) What might be some factors contributing to the problem? In your experience, what are some of the motivating factors or reasons that might contribute to this problem?

3) Are there additional challenges faced by any particular groups?

Comment on whether you believe there to be any entrenched barriers, both institutional and personal, to the retention/persistence of any particular category of students (women, low SES, or people of color, LGBT, etc.) If yes, list some of these obstacles.

4) What are some of the positive factors that might encourage or result in STEM student persistence and retention?: Identify factors or practices that you believe might keep students motivated and academically prepared to persist in STEM.

5) Make recommendations. Identify and prioritize actions that Texas State University COSE can take to increase student retention in STEM fields of study and ultimately, graduation rates in STEM baccalaureate degrees.

Analysis of the Qualitative Study Data

All participants agreed that student retention in STEM fields of study is a problem at the College of Science and Engineering.

John commented, "Yes. We have a problem both getting them into math and keeping them. The perception is that math is hard. They think they know what math studies are about, but then calculus hits them hard. Calculus is just so different. It throws everybody off. If they do poorly, they look to scale down in math or they may drop math altogether. Many are also lost at the discrete mathematics level. They struggle with the concept of proof. These are new statements and a new way of disciplined thinking that they need to follow the math rules and they are not used to this."

Sarah chimed in to note, "I have lots and lots of students that leave their intended major. They find out how challenging it is. They look at the statistics of how many students get accepted into the graduate programs and they get discouraged. Many seem to have some inability to cope with basic math. I don't think they understand how to think and re-train themselves. They are not convinced that they can do it. So yes, STEM students look around and see that not all of them will make it." 
Then participants discussed the many factors they believe lead to student retention issues.

They identified issues related to "Individual Student Experiences-Classroom Experiences and Curricular Experiences" such as a problem with large class sizes, use of technology, and challenges in implementing inquiry based instructional technologies.

David noted, "I think one of the key problem is that classes are SO big that it's difficult to have the relational experiences with students that we'd like. Usually, in my large undergraduate classes, I only get to know those students who come to my office hours. How does it get better? We need ways to break out of this."

Archie added, "Yes, I can confirm that class size is an issue at Texas State University. Maybe we need to use more technology. Maybe we need to find ways to be more 1 on 1 with our students."

Jessica noted, "I have taught large and small classes and in both I have used technology. But that is no replacement for the important student-professor interaction.

It is not a matter of us wanting to use technology. Students are already ahead of us in using technology to further their needs.

David then noted, "But it's a problem because the State is trying to reduce the cost of going to college for students and that means large class sizes. It is a quality issue."

Rahul: "In an ideal world, project based assignments would be used more often because the are better. In fact, we have been updating our labs. If we take smaller bites, we can do better. Practical, real-world connections need to be made in the classroom. We need to make things relevant. It may be worth trying to create a "major" section kind of like we are thinking of setting up a specialized course for some students."

Jessica: Yes. Students relate to real world examples. So, the trick is to figure out how to make a dry subject interesting. We need more projects and problems to give students to solve. But there is a lot to cover, so how can you make it interesting and fit it in, and at the same time, make it work for all our different students?

Salma: Part of it is also thinking about the order that we teach in. We need to think of how to make thinks relevant that are often very conceptual and abstract.

Keith: Hey, I wonder, since part of our society is so immersed in media, maybe we should be using it to solve this issue. STEM has some image problems. There are stereotypes and identity issues. And people favor good design with experiences that are motivating. Textbook publishers focus on design. We reach people through design. Maybe what we need is a designer in residence to help the faculty with good design and illustration in their instruction. It's a matter of how do we make it compelling.

The group then turned to discuss cultural differences. The facilitator asked, "Are there any groups of students on campus that might have an even more challenging times than other students in STEM on campus?"

Steve: "I can discuss African American issues. When I grew up, I was not supposed to do well in math. It was unthinkable that I should be good at it. It seemed awkward that a top notch STEM professional should be of that culture. It is a respected achievement, but it is not part of the culture."

Rosa: "As a woman, it was also unexpected that I should be at the top of the class in math when I was in high school. I was the freak show. It was me and two Asian guys at the top of the class."

Kyle: "But I think being in STEM is cooler now. In the past, STEM people were thought of as nerds. There was nothing attractive about them-I think that has changed hasn't it?" 
Steve: "I'd like to comment more about African American students. You know, we have Historically Black Colleges and Universities. These universities attract a large number of African American students because they feel accepted. This University does not have that. It needs a large cohort to grow and sustain. But we need to do something to get it there. I was at a HBCU because I wanted to help build their engineering department. And I found that it was a completely different culture than the Ivy league university at which I later taught, and now here. I know Texas State is an Hispanic serving institution, so things that support Latino students must be going on, but as a faculty member, I am not in tune. So the point is that we need to promote cultural belonging and as faculty, we need to try to understand these cues and interact with our students."

Karen: "I see what you are saying and I have a personal example. I am married to a Mexican American and if I did not have that relationship I would never think of some of the issues that they have that are related to culture. For instance, my sister in law shared that in her family it was not easy to accept sending a woman to college -because there is a monetary cost to going to college, and a family contribution cost because that young woman is not earning money. So that is a lot of pressure on a person and probably something that some of our students still experience. This seems like something that can be addressed."

Laura: "Some studies say that to begin to make a change that is sustainable, you need to have at least three faculty in a group. Like women in STEM, you need at least three in a department. One alone cannot make the change. In a greater number, there is less fear about suggesting frameworks to be set in place about teaching respectfully and with awareness of these social and cultural issues."

Hassan: "Yes, the teaching culture is sometimes also tough. In our department it's a sink and swim mentality. It's also a culture that places the blame on the student. So, if they struggle, they are blamed because "they are not smart."

Salma: "Well, and let's be honest, people who become college professors are very often not the most effective communicators. I remember going to my faculty member when I was in college and trying to talk to my professor and all he could say was 'do your homework', its about culture. I can't imagine anything more demonstrative.

Rahul: It's also a social cultural problem that STEM isn't more valued and we need to reach parents. In India, all parents want their children to study math and science so that they can study medicine and engineering. There are so many more college applications for engineering and science schools than in anything else. That culture wants their kids to go there. India is producing thousands of engineers. The parent force is cultural.

\section{Focus Group Study Findings}

As the conversation was wrapping up, the facilitator requested top recommendations for improving student retention problems. These recommendations are listed below:

- $\quad$ Provide support such as automatic tutoring. Create an automatic mentoring system. Include mentors from industry.

- $\quad$ One of the biggest factors that hurts students is bad instructors. We need to find a way to remove such instructors from teaching because they cause students to transfer out. Maybe we can identify the better professors and put them to teach the lower levels of undergraduate students and the others can be moved up to teach graduate students to a level where the students are more secure and there they can cause less damage.

- We need an agreed upon model so that faculty can spend more time on teaching. We already know how to do this. We can try a two-tier model where some focus on teaching and others on research. We would have to balance this even more for tenure track faculty.

- I Igree with classroom size being one of the main problems. There are two extremes. We want permission to have smaller classes in order to have students that can excel. The other extreme is developmental math 
but big lectures halls are not appropriate for developmental math students.

- I have taught really large courses with 225 and 320 students! And it is a problem, but I don't know if we can change that. But we can focus on things that can make it better. I would like to suggest we develop pre-lab videos. Maybe things that we have experience with. I had a very unorthodox set of experiences as a skydiver and paramedic. I think that through media, we can bring a cool factor to STEM. We need to build an effective communication department that will allow us to give access to students and to introduce and change the culture. We might be able to do this if we use short bites to help students gain access.

- I vote that its ok to focus on something superficial like physical space and design of information. We need artists on staff that can help us make things appealing and to help us create emotional connections.

- $\quad$ And I vote we organize Faculty Institutes. This university needs to gather and make changes and they need to support that. The barrier is too high. We need to allow people to gradually change and bring cultural knowledge to the forefront.

\section{OVERALL CONCLUSIONS}

The major aim of this study was to share a multi-faceted research approach to assist in identifying and understanding possible factors leading to college student retention and success. The three-part organizational selfstudy undertaken by Texas State University is presented as a model for other colleges and universities who are ready to take concrete action based on local data and needs. This approach is a grassroots approach in that it places great value upon the voice of the institution's faculty and empowers faculty to lead in studying and defining action items to address the changes desired. At Texas State University, the completed self-studies indicated several gaps in the state of performance and participation of STEM students. Principally, retention issues of STEM majors were identified in general and with underrepresented student groups in particular. Underrepresented students do not pursue STEM degrees at an equitable rate as that in which they pursue other degrees. In addition, many of those who do pursue STEM degrees seem to face additional challenges that result in a longer time to graduation. The selfstudy, framed by retention theories and balanced by other "voices" such as STEM student focus group data points to some of the following remedial measures: revising support and professional development for STEM instructors, providing supplemental instruction in math and science for students and including discipline specific introductory courses and early internship experiences to motivate early interest and cultivate the development of communities of learners. In addition, recent funding from the National Science Foundation will support further investigation and implementation of a variety of strategies and subsequent studies with larger samples sizes, greater use of quantitative analysis techniques and longitudinal impact measurement of STEM student retention.

\section{ACKNOWLEDGEMENTS}

This material is based on work supported by the National Science Foundation under grant no. DUE 1431578.

\section{AUTHOR INFORMATION}

Dr. Araceli Martinez Ortiz is Assistant Professor of Engineering Education in the College of Education at Texas State University. Araceli is Director of the LBJ Institute for STEM Education and Research and teaches graduate courses in Integrated STEM Curriculum and Methods. She collaborates on various state and national STEM education programs. Araceli holds Engineering degrees from The University of Michigan and Kettering University. She holds a Masters degree in Education from Michigan State and a PhD in Engineering Education from Tufts University. Her research interests include studying the role of engineering as a curricular context for math and science learning and developing research-based active-learning instructional models and assessment instruments to enhance engineering students' learning experiences and STEM teacher professional development.

Dr. Vedaraman Sriraman is a University Distinguished Professor of Engineering Technology and a faculty associate of the LBJ Institute for STEM Education and Research at Texas State University. Dr. Sriraman's degrees are in mechanical and industrial engineering. His research interests are in engineering education, sustainability, and applied statistics. In the past, he has implemented several grants from the NSF and SME-EF. He has also received several teaching awards at Texas State. 


\section{REFERENCES}

Astin, A. (1975). Preventing students from dropping out. San Francisco, CA: Jossey-Bass.

Astin, A. (1977). What matters most in college: Four critical years. San Francisco, CA: Jossey-Bass.

Bureau of Labor Statistics (2014). STEM 101: Intro to tomorrow's jobs. Retrieved in April, 2014 from: http://www.bls.gov/careeroutlook/subject/stem.htm

Charette, R. ( 2013). The Myth of the Science and Engineering Shortage, IEEE Spectrum. August 30, 2013. Accessed: http://spectrum.ieee.org/at-work/education/the-stem-crisis-is-a-myth

Committee on Underrepresented Groups and the Expansion of the Science and Engineering Workforce Pipeline; Committee on Science, E., and Public Policy; Policy and Global Affairs; National Academy of Sciences, National Academy of Engineering, and Institute of Medicine (2010). Expanding Underrepresented Minority Participation: America's Science and Technology Talent at the Crossroads. Washington, D.C., The National Academies Press.

Davis, C-S. G., \& Finelli, C. J. (2007, Fall). Diversity and retention in engineering. In M. Kaplan \& A. T. Miller (Eds.), The scholarship of multicultural teaching and learning (pp. 63-71). New Directions for Teaching and Learning, No. 111. San Francisco: Jossey-Bass.

Dowd, A. C., Malcom, L. E., \& Bensimon, E. M. (2009). Benchmarking the success of Latina and Latino students in STEM to achieve national graduation goals. Los Angeles, CA: Center for Urban Education.

Dowd, A.C., Malcom, L.E., \& Macias, E.E. (2010). Improving transfer access to STEM bachelor's degrees at Hispanic Serving Institutions through the America COMPETES Act. Los Angeles, CA: University of Southern California. Davis, C-S. G., \& Finelli, C. J. (2007, Fall). Diversity and retention in engineering. In M. Kaplan \& A. T. Miller (Eds.), The scholarship of multicultural teaching and learning (pp. 63-71). New Directions for Teaching and Learning, No. 111. San Francisco: Jossey-Bass.

Higher Education Research Institute, (2010). Degrees of Success Bachelor's Degree Completion Rates among Initial STEM Majors. In HERI Research Brief, January 2010. Retrieved on February, 2014 from: http://www.heri.ucla.edu/nih/downloads/2010\%20-\%20Hurtado,\%20Eagan,\%20Chang\%20$\% 20$ Degrees\%20of\%20Success.pdf

Hurtado, S., Eagan, K., Pryor, J.H., Whang, H., \& Tran, S. (Oct 2012). Undergraduate Teaching Faculty: The 20102011 HERI Faculty Survey.

Institute for Higher Education Policy, (2010) The Role of Minority-Serving Institutions in National College Completion Goals. Retrieved on April 2014: http://www.ihep.org/assets/files/publications/sz/The_Role_of_MSIs_FINAL_January_2012[1].pdf

Jensen, L. A. (2011). Bridging cultural and developmental approaches to psychology: New syntheses in theory, research and policy. New York: Oxford University Press.

Kuh, G.,\& Love., P. (2004). A cultural perspective on student departure. In J. M. Braxton (Ed.), Reworking the student departure puzzle. Nashville, TN: Vanderbilt University Press.

Longwell-Grice, R., \&Longwell-Grice, H. (2007). Testing Tinto: How do retention theories work for firstgeneration, working-class students? Journal of College Student Retention, 9(4), 407-420.

Lundquist, C., Spalding, R. \& Landrum, R.. (2002). "College Student's Thoughts About Leaving the University: The Impact of Faculty Attitudes and Behaviors". Journal of College Student Retention: Research, Theory \& Practice, 4(2), 123-133. http://dx.doi.org/10.2190/FLAL-7AM5-Q6K3-L40P

Maltese, A.V. \& Tai, R. H. (2011). Pipeline persistence: Examining the association of educational experiences with earned degrees in STEM among U.S. students. Science Education Policy 98, 877-906

Martinez Ortiz \& Sriraman (2014) Quantitative Analysis- Faculty Perceptions on Retention Issues with STEM Students. Unpublished manuscript.

Nadelson, L. \& Callahan, J. ( 2012). Promoting STEM faculty members' reflection on their learning perceptions and teaching practices. ASEE Conference Proceedings.

National Center for Education Statistics. (2005). Digest of education statistics 2005. Washington, DC

National Science Foundation (2002). Women, minorities, and persons with disabilities in science and engineering: 2002. Arlington, VA.

National Science Foundation (2006). Science and Engineering Indicators, 2006. Two volumes: vol 1-NSB 06-01, vol 2, NSB 06-01A. Arlington, VA.

National Science Foundation (2012). Science and Engineering Indicators, 2012. Available: http://www.nsf.gov/statistics/seind12/c2/c2s2.htm. Arlington, VA. 
National Science Foundation (2014). STEM CIP codes, 2014. Available: http://www.nsf.gov/statistics/seind12/c2/c2s2.htm. Arlington, VA.

National Center for Educational Statistics, (2002) Classification of Instructional Programs (CIP)- 2000: U.S. Department of Education, National Center for Education Statistics. Washington, DC: U.S. Government Printing Office.

Nora, A., \& Crisp, G. (2009). Hispanics and higher education: An overview of research, theory, and practice. In J. C. Smart (Ed.) Higher Education: Handbook of Theory and Research, 24, (pp. 321-358). Springer Publishing.

Noel-Levitz, (2012). National freshman attitudes report. Retrieved from https://www.noellevitz.com/documents/shared/Papers_and_Research/2012/2012\%20National\%20Freshma n\%20Attitudes\%20Report.

Pascarella, E. T. \& Terenzini, P. T. (2005) How college affects students, vol 2: A third decade of research. San Francisco: Jossey-Bass.

Pew Research Center, (2014). In 2014, Latinos will surpass whites as largest racial/ethnic group in California. Retrieved on January,2014 from: http://www.pewresearch.org/fact-tank/2014/01/24/in-2014-latinos-willsurpass-whites-as-largest-racialethnic-group-in-california/

President's Council of Advisors on Science and Technology, Prepare and Inspire: K-12

Education in Science, Technology, Engineering, and Math (STEM) for America's Future (2010), Washington, DC. http://www.whitehouse.gov/sites/default/files/microsites/ostp/pcast-stemed-report.pdf.

Reason, R. D. (2009). An examination of persistence research through the lens of a comprehensive conceptual framework. Journal of College Student Development 50(6), 659-682.

Rendón, L.,Jalomo, R., \& Nora, A. (2004). Theoretical considerations in the study of minority student retention in higher education. In J. M. Braxton (Ed.), Reworking the student departure puzzle. Nashville, TN: Vanderbilt University Press.

Seymour, E. \& Hewitt, N.M. (1997). Talking about leaving: Why undergraduates leave the sciences. Boulder, CO: Westview Press.

Spady, W. G. (1971). Dropouts from higher education: Toward and empirical model. Interchange, 2(3), 38-62.

Teitelbaum,M. (2014). The Myth of the Science and Engineering Shortage, The Atlantic. March 19, 2014. Accessed: http://www.theatlantic.com/education/archive/2014/03/the-myth-of-the-science-andengineering-shortage/284359/

Texas Comptroller of Public Accounts (2014). The Texas Economy- Economic Outlook. Retrieved May 2013 from: http://thetexaseconomy.org/economic-outlook/

Texas Higher Education Coordinating Board (2013). University Accountability Measures and Definitions. Retrieved January, 2013 from: http://www.thecb.state.tx.us/reports/pdf/1715.pdf?CFID=15748436\&CFTOKEN=96155528

Tierney, W. (2004). Power, identity, and the dilemma of college student departure.

In J. M. Braxton (Ed.), Reworking the student departure puzzle. Nashville, TN: Vanderbilt University Press.

Tinto, V. (1975). Dropout from higher education: a theoretical synthesis of recent research. Review of Educational Research in Higher Education 45(1), 89-125.

Tinto, V. (1987). Leaving college: Rethinking the causes and cures of student attrition (1st Ed.). Chicago, IL: University of Chicago Press.

Tinto, V. (1993). Leaving college: Rethinking the causes and cures of student attrition (2nd Ed.). Chicago, IL: University of Chicago Press.

Tinto, V. (2007). Research and practice of student retention: What next? Journal of College Student Retention. 8(1), $1-20$.

U.S. Department of Commerce and the National Economic Council (2012) Competitiveness and Innovative Capacity of the United States Report. Washington, D.C. Published by The U.S. Department of Commerce.

U.S. Census Bureau, (2013). United States Population Projections: 2000 to 2050- The 2009 National Population Projections. Retrieved on May 1, 2013 from: http://www.census.gov/population/projections/files/analyticaldocument09.pdf

Young, H. (2005). Secondary education systematic issues: Addressing possible contributors to a leak in the science education pipeline and potential solutions. Journal of Science Education \& Technology, (14)2, 205-216. 